\title{
Patients with advanced non-small cell lung cancer with EGFR mutations in addition to complex mutations treated with osimertinib have a poor clinical outcome: A real-world data analysis
}

\author{
NIJIA CHANG ${ }^{1}$, JINGJING DUAN $^{1}$, LINGXIONG WANG $^{2}$, ZHOUHUAN DONG $^{3}$ and ZHEFENG LIU $^{2}$ \\ ${ }^{1}$ Chinese People's Liberation Army Medical School; Departments of ${ }^{2}$ Oncology and ${ }^{3}$ Pathology, \\ Chinese People's Liberation Army General Hospital, Beijing 100853, P.R. China
}

Received July 1, 2019; Accepted April 9, 2020

DOI: $10.3892 /$ ol.2020.11801

\begin{abstract}
The present study aimed to investigate the clinical characteristics and outcomes of patients with advanced non-small cell lung cancer (NSCLC) treated with osimertinib, and focused on the resistance mechanism to osimertinib in a real-world setting. Data from 128 patients with advanced NSCLC who were treated with osimertinib between March 2015 and November 2018 at the Chinese People's Liberation Army General Hospital (Beijing, China) were retrospectively collected, and the associations between mutation types and survival were analysed. In patients treated with osimertinib, the objective response rate reached $60.9 \%$ (78/128) and the disease control rate reached $81.3 \%$ (104/128), with a median progression-free survival (PFS) time of 12.2 months. A number of complex mutations were identified in the re-analysis after the development of osimertinib resistance, including TP53, KRAS and PIK3CA mutations, epidermal growth factor receptor (EGFR) and MYC amplifications, and mutations associated with SCLC transformation, demonstrating that these mutations may account for osimertinib resistance. The median PFS time for patients with the EGFR T790M mutation ( $n=41)$ was significantly longer than that for patients with the T790M mutation and the aforementioned complex mutations $(\mathrm{n}=13)(16.7$ vs. 10.8 months; $\mathrm{P}=0.001)$. Patients with a single EGFR mutation $(n=87)$ had a longer median PFS time than those with an EGFR mutation and complex mutations $(n=24)$ (14.63 vs. 6.63 months; $P<0.0001)$. In conclusion, the present study analysed the effects of osimertinib in patients with advanced NSCLC with EGFR mutations, particularly
\end{abstract}

Correspondence to: Dr Zhefeng Liu, Department of Oncology, Chinese People's Liberation Army General Hospital, 28 Fuxing Road, Beijing 100853, P.R. China

E-mail: 1zf1220@sina.com

Key words: non-small cell lung cancer, osimertinib, resistance mechanism
T790M mutations. The results indicated that the efficacy of osimertinib was weakened when patients had complex mutations, suggesting that complex mutations may be responsible for resistance to osimertinib.

\section{Introduction}

A systematic review and meta-analysis has demonstrated that the epidermal growth factor receptor (EGFR) mutation global prevalence in patients with non-small cell lung cancer (NSCLC) is $32.3 \%$, which is different to the prevalence in the European population (14.1\%), but similar to that in China (38.4\%) (1). Exon 19 deletions and exon 21 L858R mutations are the most common mutations (2). The T790M point mutation occurs in $50-60 \%$ of patients and confers resistance to first-generation tyrosine kinase inhibitors (TKIs) (2-4).

For patients with wild-type EGFR and no resistance mutations, especially the T790M mutation, osimertinib is an effective third-generation irreversible inhibitor $(5,6)$. FLAURA Clinical Trials (Funded by AstraZeneca) have demonstrated that previously untreated EGFR-mutant patients treated with osimertinib had a significantly longer median progression-free survival (PFS) time than those treated with standard EGFR-TKIs (18.9 vs. 10.2 months) (7). Similar results were obtained in an Asian study (8).

However, the inclusion criteria for participation in clinical trials are often so stringent that most patients in clinical practice are unable to participate (9). In the real world, some patients may progress rapidly and have a short PFS time, and this may be associated with resistance mutations. Mechanisms of acquired resistance to first-generation EGFR-TKIs include the T790M point mutation and other gene alterations in PIK3CA, human epidermal growth factor receptor 2 (HER2) and KRAS (10). However, to the best of our knowledge, there has not been a clinical study to confirm the resistance mechanism to osimertinib. The present study revealed, from a clinical perspective, that patients with an EGFR mutation in addition to complex mutations experienced poor survival, and examined the resistance mechanism of osimertinib. Therefore, more comprehensive genetic tests are required for patients treated with osimertinib. 


\section{Patients and methods}

Patients. Data from 128 patients treated with osimertinib diagnosed with NSCLC between March 2015 and November 2018 at the Chinese People's Liberation Army General Hospital (Beijing, China) were collected for the present study. Tissue for diagnosis was obtained by biopsy. Inclusion criteria were as follows: i) NSCLC patients diagnosed by histological examination; ii) osimertinib used during treatment; iii) measurable lesion by CT or MRI scan; and iv) age $>18$ years. Exclusion criteria were: i) Patients that receive other treatments at the same time, such as biological immunotherapy, radiotherapy, etc.; ii) other malignant tumors that are not cured; iii) severe dysfunction of important organs such as heart, liver and kidney and iv) severe history of drug allergy. The diagnosis and staging of patients was based on National Comprehensive Cancer Network (NCCN) clinical practice guidelines (11). Among the 128 patients with NSCLC, 124 (96.9\%) were diagnosed with adenocarcinoma, 3 (2.3\%) with adenosquamous carcinoma and $1(0.8 \%)$ with large cell carcinoma. A total of 125 patients were diagnosed with stage IV disease, while 3 were diagnosed with stage IIIB disease. In addition, 111 patients had EGFR mutations according to next-generation sequencing results and 82 patients underwent a further biopsy after progression on first-generation EGFR-TKIs. The details of the patient characteristics and EGFR mutation types are presented in Tables Iand II.

EGFR mutation detection. The molecular diagnostic method used in the present study was next-generation sequencing. First, a clinical pathologist evaluated the tumour content ( $\geq 30 \%$ ) to confirm the adequacy of the sample for sequencing. A DNA FFPE Tissue kit (Qiagen $\mathrm{GmbH}$ ) was used according to the manufacturer's instructions to extract DNA from 5- $\mu \mathrm{m}$ paraffin sections, and then standard sequencing was used to analyse the tissues after library preparation, hybrid capture and library quality assurance (12).

Treatment and clinical assessment. Oral osimertinib (Tagrisso $^{\mathrm{TM}}$; AZD9291; AstraZeneca PLC) was administered at a dose of $80 \mathrm{mg}$ /day until disease progression (from 0.20-38.6 months, one patient died 0.2 months after trying osimertinib at the end of the systemic metastatic disease without T790M detection). Clinical follow-up assessments were performed, including radiological evaluations at an average of every 4-6 weeks, physical examinations were performed if patients were coughing or had another discomfort. Molecular pathological analyses by next-generation sequencing were performed when disease progression had been confirmed by CT or MRI scan in every 4-6 weeks of examination. Experienced investigators evaluated the treatment response according to the Response Evaluation Criteria In Solid Tumours 1.1 guidelines (13). The PFS time of the patients with osimertinib treatment was the main study end point, and PFS time was defined as the time from the beginning of osimertinib treatment to disease progression or to the last follow-up date (October 31, 2018). The efficacy of osimertinib treatment was represented by the objective response rate (ORR) and the disease control rate (DCR). The ORR included patients with a partial response (PR) or complete response
Table I. Baseline characteristics of patients $(n=128)$.

\begin{tabular}{|c|c|}
\hline Characteristics & Value \\
\hline $\begin{array}{l}\text { Median age at start of } \\
\text { first treatment (range), years }\end{array}$ & $57(28-90)$ \\
\hline \multicolumn{2}{|l|}{$\operatorname{Sex}, \mathrm{n}(\%)$} \\
\hline Female & $79(61.7)$ \\
\hline Male & $49(38.3)$ \\
\hline \multicolumn{2}{|l|}{ Smoking history, n (\%) } \\
\hline Smoker & $33(25.8)$ \\
\hline Non-smoker & $95(74.2)$ \\
\hline \multicolumn{2}{|l|}{ Histology, n (\%) } \\
\hline Adenocarcinoma & $124(96.9)$ \\
\hline Others & $4(3.1)$ \\
\hline \multicolumn{2}{|l|}{ Clinical stage, n (\%) } \\
\hline IV & $125(97.7)$ \\
\hline IIIB & $3(2.3)$ \\
\hline \multicolumn{2}{|l|}{ Performance status, n (\%) } \\
\hline 0 & $89(69.5)$ \\
\hline 1 & $7(5.5)$ \\
\hline 2 & $23(17.9)$ \\
\hline 3 & $7(5.5)$ \\
\hline 4 & $2(1.6)$ \\
\hline \multicolumn{2}{|l|}{ Presence of metastasis, n (\%) } \\
\hline None & $13(10.1)$ \\
\hline Brain & $44(34.4)$ \\
\hline Bone & $60(46.9)$ \\
\hline Liver & $11(8.6)$ \\
\hline \multicolumn{2}{|c|}{ Number of metastatic organs, n (\%) } \\
\hline 1 & $49(38.3)$ \\
\hline 2 & $52(40.6)$ \\
\hline$\geq 3$ & $27(21.1)$ \\
\hline
\end{tabular}

(CR), and the DCR included patients with stable disease (SD), PR or CR.

Statistical analysis. The Kaplan-Meier method was used to analyse PFS and overall survival (OS) times, and the median PFS values between different groups were compared using log-rank tests. Paired Student's t-test was used to analyse the measurement data in Table SI, and the $\chi^{2}$ test/Fisher's exact test was used to analyse categorical data. $\mathrm{P}<0.05$ (two-sided) was considered to indicate a statistically significant difference. SPSS v22.0 (IBM Corp.) was used to perform statistical analyses, and survival curves were generated with GraphPad Prism v7.0 (GraphPad Software, Inc.).

\section{Results}

Types of mutations and survival in the 128 patients. A total of 128 patients with sufficient case report data were available for analysis. A total of $120(93.8 \%)$ patients had at least one genetic test, which identified $111(86.7 \%)$ patients with EGFR mutations. In the present study, 17 patients still required the 
Table II. EGFR mutations of all patients $(n=128)$.

\begin{tabular}{|c|c|c|c|c|c|c|}
\hline $\begin{array}{l}\text { EGFR } \\
\text { mutation }\end{array}$ & $\begin{array}{l}\text { Exon } \\
18^{+}, \mathrm{n}\end{array}$ & $19 \mathrm{del}^{+}, \mathrm{n}$ & $21 \mathrm{~L} 858 \mathrm{R} / \mathrm{L} 861 \mathrm{Q}^{+,} \mathrm{n}$ & $\begin{array}{c}\text { Exon } \\
18 / 19 / 21^{-}, \mathrm{n}\end{array}$ & $\begin{array}{c}\text { Exon18/19/21 } \\
\text { unknown, n }\end{array}$ & Total, n (\%) \\
\hline Primary $\mathrm{T} 790 \mathrm{M}^{+}$ & 1 & 3 & 3 & 1 & 0 & $8(6.3)$ \\
\hline Acquired T790M ${ }^{+}$ & 0 & 21 & 22 & 2 & 1 & $46(35.9)$ \\
\hline $\mathrm{T}^{2} 90 \mathrm{M}^{-}$ & 0 & 14 & 17 & 4 & 0 & $35(27.3)$ \\
\hline T790M unknown & 1 & 10 & 15 & 5 & 8 & $39(30.5)$ \\
\hline Total, n (\%) & $2(1.6)$ & $48(37.5)$ & $57(44.5)$ & $12(9.4)$ & $9(7.0)$ & $128(100.0)$ \\
\hline
\end{tabular}

EGFR, epidermal growth factor receptor.
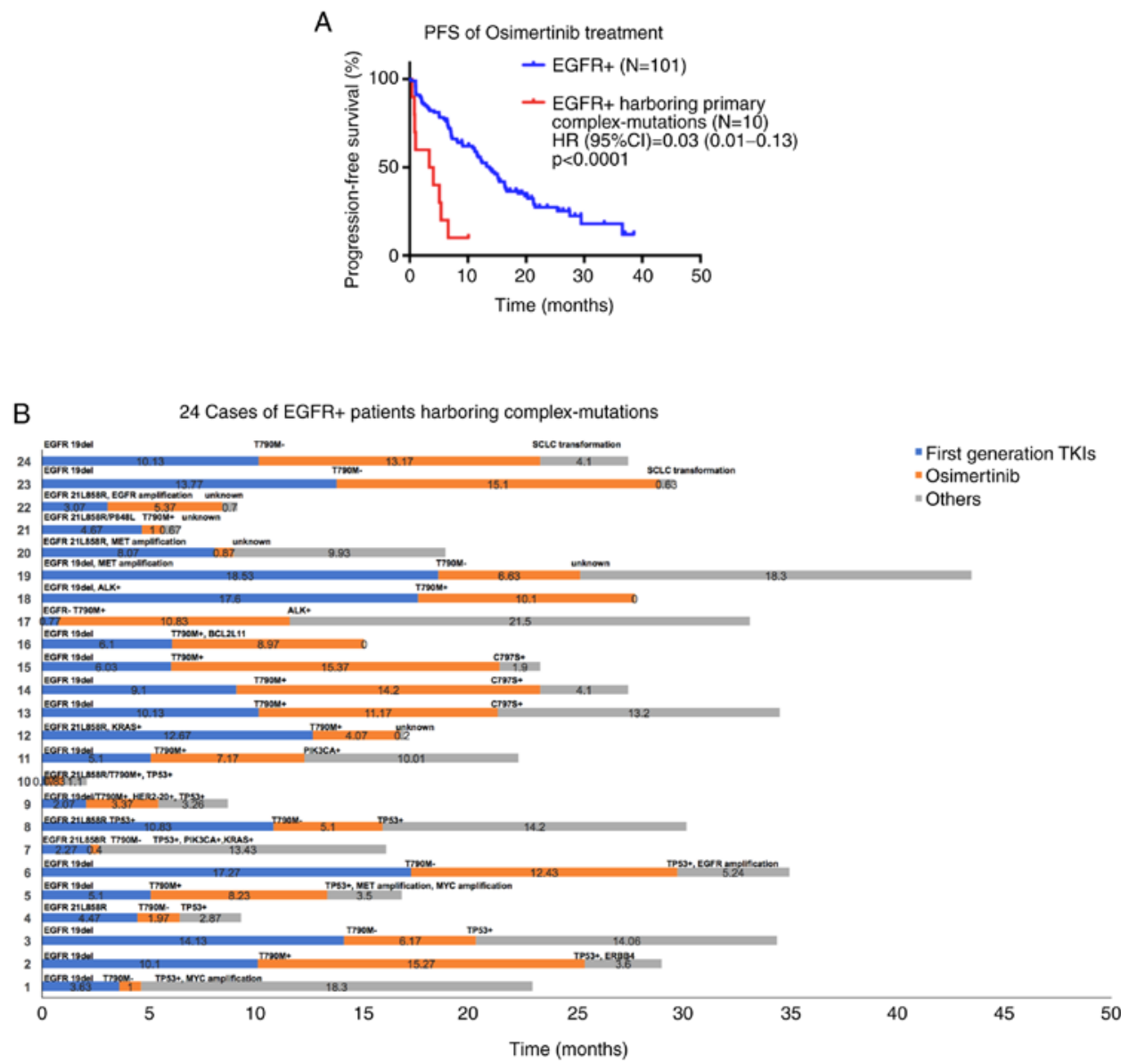

C Acquired complex-mutations evolution

EGFR-TKI EGFR-TKI Osimertinib Osimertinib

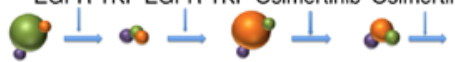

Primary complex-mutations evolution

EGFR-TKI EGFR-TKI Osimertinib Osimertinib

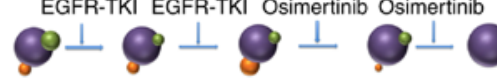

- Number of tumor cells with EGFR ${ }^{19 d e l} / \mathrm{EGFR}^{21 L 858 R}$ or Nuer sensitue mutations

ells with complex-mutations

- Number of tumor cells with EGFR ${ }^{\text {T790M }}$ mutation

Figure 1. (A) Kaplan-Meier survival curves for the PFS of 10 patients with primary complex mutations vs. 101 patients with single EGFR mutations (median PFS time, 3.4 months and 95\% CI, 0.0-8.1, vs. median PFS, 13.7 months and 95\% CI, 10.8-16.6, respectively; P<0.0001). (B) Patients with EGFR mutations harbouring additional complex mutations. (C) Schematic diagram representing that tumours with resistance to osimertinib may be heterogeneous, consisting of the EGFR19del/L858R mutation or other sensitivity-associated mutations (green) or the EGFRT790M mutation (orange), and harbour complex mutations (purple). PFS, progression-free survival; EGFR, epidermal growth factor receptor; HR, hazard ratio; TKI, tyrosine kinase inhibitor. 
A PFS of Osimertinib treatment
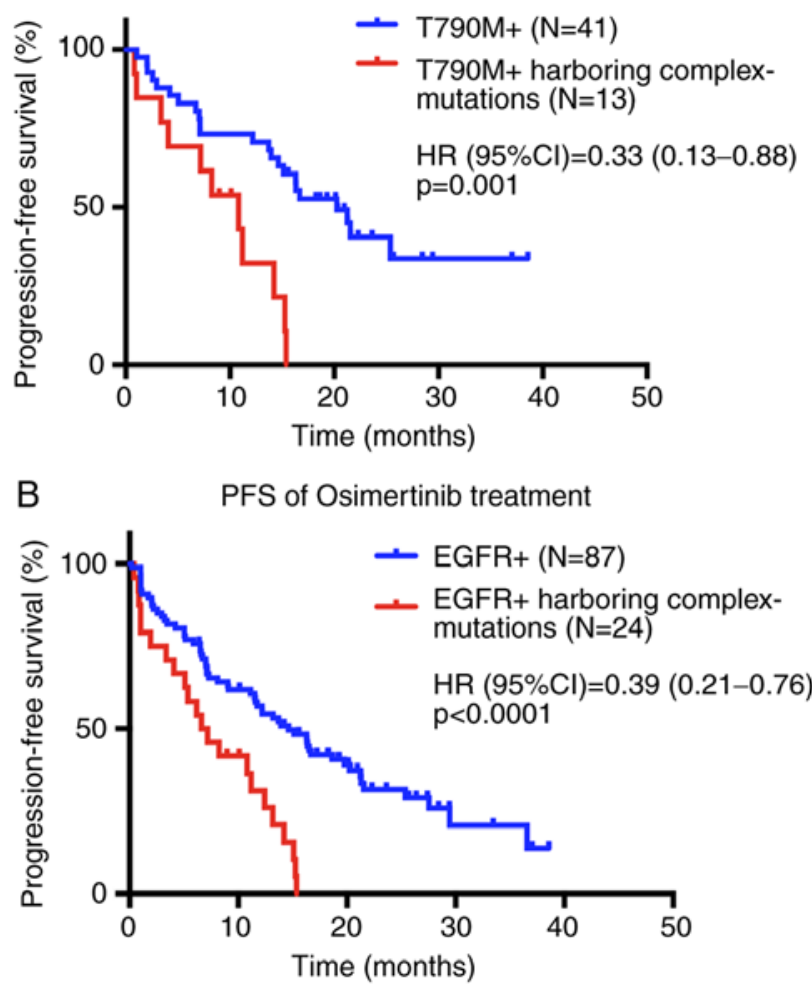

Figure 2. (A) Kaplan-Meier survival curves for the PFS of 41 patients with the T790M mutation vs. 13 patients with the T790M mutation and additional resistance mutations (median PFS time, 20.2 months and 95\% CI, 10.5-25.9, vs. median PFS time, 10.8 months and 95\% CI, 5.1-16.5, respectively; P=0.001). (B) Kaplan-Meier survival curves for the PFS of 87 patients with EGFR mutations and 24 patients with EGFR and complex mutations (median PFS time, 14.6 months and 95\% CI, 10.6-18.7, vs. median PFS, 6.6 months and 95\% CI, 3.2-10.1, respectively; P<0.0001). PFS, progression-free survival; EGFR, epidermal growth factor receptor; HR, hazard ratio.

Table III. Osimertinib treatment summary.

\begin{tabular}{lc}
\hline Characteristics & Value \\
\hline Osimertinib users, $\mathrm{n}(\%)$ & $128(100)$ \\
EGFR ${ }^{+}$mutation, $\mathrm{n}(\%)$ & $111(86.7)$ \\
$\mathrm{T} \mathrm{m} \mathrm{M}^{+}$mutation, $\mathrm{n}(\%)$ & $54(42.2)$ \\
Efficacy of osimertinib & \\
treatment, $\mathrm{n}(\%)$ & \\
$\mathrm{CR}$ & $0(0)$ \\
$\mathrm{PR}$ & $78(60.9)$ \\
$\mathrm{SD}$ & $26(20.3)$ \\
$\mathrm{PD}$ & $24(18.8)$ \\
ORR & $78(60.9)$ \\
DCR & $104(81.3)$ \\
mPFS, months & $12.17(95 \% \mathrm{CI}, 10.6-13.8)$ \\
mOS, months & $29.33(95 \% \mathrm{CI}, 27.1-31.6)$ \\
\hline
\end{tabular}

EGFR, epidermal growth factor receptor; $\mathrm{PD}$, progressive disease; ORR, objective response rate; DCR, disease control rate; mPFS, median progression-free survival; mOS, median overall survival.

use of osimertinib, although those patients did not have EGFR mutations or the EGFR mutations were not detected. The presence of an EGFR mutation did not affect the PFS time in the present study (patients with EGFR mutation vs. patients without EGFR mutation; median PFS time, 12.2 months and 95\% CI, 9.7-14.7, vs. median PFS time, 11.6 months and 95\% CI, 7.7-15.5, respectively; $\mathrm{P}=0.369$ ) (Fig. S1). The DCR was $81.3 \%$ $(104 / 128)$, with 78 patients $(60.9 \%)$ achieving PR. The median PFS of all the patients was 12.17 months (95\% CI, 10.6-13.8). A total of $45(35.2 \%)$ patients died, and the median OS was 29.33 months (95\% CI, 27.1-31.6) (Fig. S2). The osimertinib treatment summary is shown in Table III.

Types of complex mutations and poor clinical outcomes in patients. Among the 111 patients with EGFR mutations, additional complex mutations were identified in 24 patients. Ten of them had primary complex mutations (before the use of osimertinib) and 14 of them had acquired complex mutations (after the use of osimertinib). These additional complex mutations included TP53 mutations (usually in association with other mutations), the C797S mutation, MYC amplification, EGFR amplification, KRAS or PIK3CA mutations, SCLC transformation-associated mutations, B-cell lymphoma 2-like 11 (BIM) deletion polymorphisms, HER2 exon 20 insertions and ALK rearrangements (Fig. 1B). Patients with these primary complex mutations had a significantly shorter median PFS time compared with those without the same mutations before the use of osimertinib (3.4 months and 95\% CI, 0.0-8.1, vs. 13.7 months and 95\% CI, 10.8-16.6, respectively; $\mathrm{P}<0.0001$; Fig. 1A). Patients with the acquired complex mutations had a significantly shorter median PFS time compared with those 
without the same mutations after the use of osimertinib (11.2 vs. 14.6 months; 95\% CI, 8.5-13.9 and 95\% CI, 10.6-18.6, respectively; $\mathrm{P}=0.0206$; Fig. S3). These results demonstrated that these mutations may be responsible for osimertinib resistance. Our schematic diagram showing different patterns of the primary/acquired complex-mutations evolution. (Fig. 1C)

Patients with EGFR and complex mutations. The median PFS time of 41 patients with the EGFR T790M mutation, in which threonine at position 790 of exon 20 is replaced by methionine (14), was significantly longer than that of the 13 patients with the T790M mutation and the aforementioned complex mutations (20.2 months and 95\% CI, 10.5-25.9, vs. 10.8 months and 95\% CI, 5.1-16.5, respectively; $\mathrm{P}=0.001$; Fig. 2A). The basic characteristics of these 54 patients are shown in Table SI.

Additionally, the median PFS time of the 87 patients with EGFR mutations was significantly longer than that of the 24 patients with EGFR and complex mutations (14.6 months and 95\% CI, 10.62-18.65, vs. 6.6 months and 95\% CI, 3.19-10.07, respectively; P<0.0001; Fig. 2B). The basic characteristics of these patients are shown in Table SII.

\section{Discussion}

Osimertinib has been recommended by the National Comprehensive Cancer Network guidelines for untreated patients with advanced NSCLC with EGFR mutations. However, not all patients with EGFR mutations benefit from this drug $(7,11)$. Therefore, it is important to distinguish patients that will benefit from osimertinib from those that will be resistant.

Previous studies have revealed resistance mechanisms to osimertinib (12-17). The EGFR C797S mutation is a common resistance mutation that was first identified by Thress et al (10) via next-generation sequencing of cell-free plasma DNA. Previous studies have demonstrated that resistance to third-generation EGFR inhibitors is promoted by the C797S mutation (15), and that patients treated with osimertinib can use EAI045 in combination with cetuximab or brigatinib after the development of C797S resistance mutations $(16,17)$. In the present study, three patients developed a C797S mutation after osimertinib treatment; these patients had a primary EGFR 19del mutation, and PFS time was $>11$ months when they were treated with osimertinib. Patients with resistance due to C797S mutations may have a longer PFS time than those with other mutations, such as HER-2 exon 20 insertions.

There are numerous other EGFR-related mutations associated with resistance mechanisms, such as the EGFR P848L mutation (18-22), EGFR amplification $(23,24)$, MET amplification (25,26), HER2 mutations $(27,28)$, PIK3CA mutations (29-31) and mutations activating the RAS-MAPK signalling pathway (32-35). The present study revealed that a patient with the EGFR21L858R, P848L/T790M mutations experienced rapid progression after TKI treatment, including osimertinib. Therefore, complete genetic testing should be performed when selecting TKI treatments, and it is important to distinguish sensitivity mutations from resistance mutations. The present study suggested that one of the potential resistance mechanisms to osimertinib was MET amplification, even in the presence of an EGFR mutation. Patients with NSCLC with EGFR mutations harbouring MET amplifications may require a MET inhibitor after osimertinib progression. A T790M-mutation patient harbouring the HER2 exon 20 insertion displayed a 3.37-month PFS time after osimertinib treatment in the present study. The HER2 exon 20 insertion is a factor that may influence the efficacy of EGFR-TKIs.

Other mutations, such as mutations associated with SCLC transformation (36-38), BIM deletion polymorphisms $(39,40)$, TP53 mutations $(41,42)$ and ALK rearrangements $(43,44)$, may influence the PFS in patients treated with osimertinib. In the present study, 10 patients with dual TP53/EGFR mutations displayed a shorter PFS following the use of osimertinib than patients without these mutations.

The aforementioned studies suggest that these mutations may be important factors limiting the efficacy of osimertinib. Future studies should investigate novel therapeutic targets for NSCLC. Dual-targeting antibodies and combination therapies may provide benefits for patients with EGFR and additional complex mutations.

In conclusion, the present study investigated the effects of osimertinib in patients with advanced NSCLC with EGFR mutations, particularly T790M mutations. The present results indicate that the efficacy of osimertinib is weakened in patients with complex mutations, suggesting that complex mutations may be responsible for the resistance to osimertinib.

\section{Acknowledgements}

Not applicable.

\section{Funding}

No funding was received.

\section{Availability of data and materials}

All data generated or analyzed during this study are included in this published article.

\section{Authors' contributions}

NC conceived and designed the study, drafted the manuscript and revised it for important intellectual content. ZL made substantial contributions to conception and design and given final approval of the version to be published. JD, LW and ZD collected and analysed the data. All authors have read and approved the manuscript.

\section{Ethics approval and consent to participate}

The present study was approved by the director of the Department of Oncology at Chinese People's Liberation Army General Hospital (Beijing, China). The authors were able to review the patients' case records and obtain relevant information (Data S1). The patients gave oral consent to receive the targeted therapy while receiving treatment and agreed to the researchers reviewing their case records.

\section{Patient consent for publication}

The patients referred to in this study provided consent for the publication of their information. 


\section{Competing interests}

The authors declare that they have no competing interests.

\section{References}

1. Zhang YL, Yuan JQ, Wang KF, Fu XH, Han XR, Threapleton D, Yang ZY, Mao C and Tang JL: The prevalence of EGFR mutation in patients with non-small cell lung cancer: A systematic review and meta-analysis. Oncotarget 7: 78985-78993, 2016.

2. Massarelli E, Johnson FM, Erickson HS, Wistuba II and Papadimitrakopoulou V: Uncommon epidermal growth factor receptor mutations in non-small cell lung cancer and their mechanisms of EGFR tyrosine kinase inhibitors sensitivity and resistance. Lung Cancer 80: 235-241, 2013.

3. Sequist LV, Waltman BA, Dias-Santagata D, Digumarthy S, Turke AB, Fidias P, Bergethon K, Shaw AT, Gettinger S, Cosper AK, et al: Genotypic and histological evolution of lung cancers acquiring resistance to EGFR inhibitors. Sci Transl Med 3: 75ra26, 2011.

4. Yu HA, Arcila ME, Rekhtman N, Sima CS, Zakowski MF, Pao W, Kris MG, Miller VA, Ladanyi M and Riely GJ: Analysis of tumor specimens at the time of acquired resistance to EGFR-TKI therapy in 155 patients with EGFR-mutant lung cancers. Clin Cancer Res 19: 2240-2247, 2013.

5. Paez JG, Jänne PA, Lee JC, Tracy S, Greulich H, Gabriel S, Herman P, Kaye FJ, Lindeman N, Boggon TJ, et al: EGFR mutations in lung cancer: Correlation with clinical response to gefitinib therapy. Science 304: 1497-1500, 2004

6. Pao W, Miller V, Zakowski M, Doherty J, Politi K, Sarkaria I, Singh B, Heelan R, Rusch V, Fulton L, et al: EGF receptor gene mutations are common in lung cancers from 'never smokers' and are associated with sensitivity of tumors to gefitinib and erlotinib. Proc Natl Acad Sci USA 101: 13306-13311, 2004.

7. Soria JC, Ohe Y, Vansteenkiste J, Reungwetwattana T, Chewaskulyong B, Lee KH, Dechaphunkul A, Imamura F, Nogami N, Kurata T, et al; FLAURA Investigators: Osimertinib in Untreated EGFR-Mutated Advanced Non-Small-Cell Lung Cancer. N Engl J Med 378: 113-125, 2018.

8. Cho BC, Chewaskulyong B, Lee KH, Dechaphunkul A, Sriuranpong V, Imamura F, Nogami N, Kurata T, Okamoto I, Zhou C, et al: Osimertinib versus Standard of Care EGFR TKI as First-Line Treatment in Patients with EGFRm Advanced NSCLC: FLAURA Asian Subset. J Thorac Oncol 14: 99-106, 2019.

9. Okamoto I, Morita S, Tashiro N, Imamura F, Inoue A, Seto T, Yamamoto N, Ohe Y, Nakagawa K and Fukuoka M: Real world treatment and outcomes in EGFR mutation-positive non-small cell lung cancer: Long-term follow-up of a large patient cohort. Lung Cancer 117: 14-19, 2018.

10. Thress KS, Paweletz CP, Felip E, Cho BC, Stetson D, Dougherty B, Lai Z, Markovets A, Vivancos A, Kuang Y, et al: Acquired EGFR C797S mutation mediates resistance to AZD9291 in non-small cell lung cancer harboring EGFR T790M. Nature Medicine, 21: $560-562,2015$

11. National Comprehensive Cancer Network (NCCN): NCCN Guidelines ${ }^{\circledR}$ Insights - Non-Small Cell Lung Cancer, Version 5, 2018. https://education.nccn.org/node/83667.

12. Wang S, Yan B, Zhang Y, Xu J, Qiao R, Dong Y, Zhang B, Zhao Y, Zhang L, Qian J, et al: Different characteristics and survival in non-small cell lung cancer patients with primary and acquired EGFR T790M mutation. Int J Cancer 144: 2880-2886, 2019.

13. Eisenhauer EA, Therasse P, Bogaerts J, Schwartz LH, Sargent D, Ford R, Dancey J, Arbuck S, Gwyther S, Mooney M, et al: New response evaluation criteria in solid tumours: Revised RECIST guideline (version 1.1). Eur J Cancer 45: 228-247, 2009.

14. Gao J, Li HR, Jin C, Jiang JH and Ding JY: Strategies to overcome acquired resistance to EGFR TKI in the treatment of non-small cell lung cancer. Clin Transl Oncol 21: 1287-1301, 2019.

15. Niederst MJ, Hu H, Mulvey HE, Lockerman EL, Garcia AR, Piotrowska Z, Sequist LV and Engelman JA: The Allelic Context of the C797S Mutation Acquired upon Treatment with Third-Generation EGFR Inhibitors Impacts Sensitivity to Subsequent Treatment Strategies Cancer Therapy. Clin Cancer Res: doi: 10.1158/1078-0432.CCR-15-0560.

16. Jia Y, Yun CH, Park E, Ercan D, Manuia M, Juarez J, Xu C, Rhee K, Chen T, Zhang H, et al: Overcoming EGFR(T790M) and EGFR(C797S) resistance with mutant-selective allosteric inhibitors. Nature 534: 129-132, 2016.
17. Uchibori K, Inase N, Araki M, Kamada M, Sato S, Okuno Y, Fujita N and Katayama R: Brigatinib combined with anti-EGFR antibody overcomes osimertinib resistance in EGFR-mutated non-small-cell lung cancer. Nat Commun 8: 14768, 2017.

18. Yamamoto $\mathrm{H}$, Yatabe $\mathrm{Y}$ and Toyooka S: Inherited lung cancer syndromes targeting never smokers. Transl Lung Cancer Res 7: 498-504, 2018

19. Han B, Zhou X, Zhang RX, Zang WF, Chen ZY, Song HD, Wan HY and Zheng CX: Mutations of the epidermal growth factor receptor gene in NSCLC patients. Oncol Lett 2: 1233-1237, 2011.

20. Zheng D, Hu M, Bai Y, Zhu X, Lu X, Wu C, Wang J, Liu L, Wang Z, Ni J, et al: EGFR G796D mutation mediates resistance to osimertinib. Oncotarget 8: 49671-49679, 2017.

21. Menon R, Müller J, Schneider P, Lakis S, Thress K, Wolf J, Heukamp L, Heuckmann JM and Griesinger F: A novel EGFR (C797) variant detected in a pleural biopsy specimen from an osimertinib-treated patient using a comprehensive hy- brid capture-based next-generation sequencing assay $(\mathrm{J})$. J Thorac Oncol 11: e105-e107, 2016.

22. Bersanelli M,Minari R, Bordi P, Gnetti L, Bozzetti C, Squadrilli A, Lagrasta CA, Bottarelli L, Osipova G, Capelletto E, et al: L718Q mutation as new mechanism of acquired resistance to AZD9291 in EG- FR- mutated NSCLC(J). J Thorac Oncol 11: e121-e123, 2016

23. Knebel FH, Bettoni F, Shimada AK, Cruz M, Alessi JV, Negrão MV, Reis LFL, Katz A and Camargo AA: Sequential liquid biopsies reveal dynamic alterations of EGFR driver mutations and indicate EGFR amplification as a new mechanism of resistance to osimertinib in NSCLC. Lung Cancer 108: 238-241, 2017.

24. Ercan D, Zejnullahu K, Yonesaka K, Xiao Y, Capelletti M, Rogers A, Lifshits E, Brown A, Lee C, Christensen JG, et al: Amplification of EGFR T790M causes resistance to an irreversible EGFR inhibitor. Oncogene 29: 2346-2356, 2010.

25. Wang Y, Li L, Han R, Jiao L, Zheng J and He Y: Clinical analysis by next-generation sequencing for NSCLC patients with MET amplification resistant to osimertinib. Lung Cancer 118: 105-110, 2018.

26. Ou SI, Agarwal N and Ali SM: High MET amplification level as a resistance mechanism to osimertinib (AZD9291) in a patient that symptomatically responded to crizotinib treatment post-osimertinib progression. Lung Cancer 98: 59-61, 2016.

27. Planchard D, Loriot Y, André F, Gobert A, Auger N, Lacroix L and Soria JC: EGFR-independent mechanisms of acquired resistance to AZD9291 in EGFR T790M-positive NSCLC patients. Ann Oncol 26: 2073-2078, 2015.

28. Liu S, Li S, Hai J, Wang X, Chen T, Quinn MM, Gao P, Zhang Y, Ji H, Cross DAE, et al: Targeting HER2 Aberrations in Non-Small Cell Lung Cancer with Osimertinib. Clin Cancer Res 24: 2594-2604, 2018.

29. Oxnard GR, Thress K, Paweletz C, Stetson D, Dougherty Lai BZ, Markovets A, Felip AE, Vivancos A, Kuang Y, et al: ORAL17.07-Mechanisms of Acquired Resistance to AZD9291 in EGFR T790M Positive Lung Cancer. In: Proceedings of the WCLC 2015 - 16th World Conference on Lung Cancer, Denver, CO, 2015

30. Chaft JE, Arcila ME, Paik PK, Lau C, Riely GJ, Pietanza MC, Zakowski MF, Rusch V, Sima CS, Ladanyi M, et al: Coexistence of PIK3CA and other oncogene mutations in lung adenocarcinoma-rationale for comprehensive mutation profiling. Mol Cancer Ther 11: 485-491, 2012.

31. Ludovini V, Bianconi F, Pistola L, Chiari R, Minotti V, Colella R, Giuffrida D, Tofanetti FR, Siggillino A, Flacco A, et al: Phosphoinositide-3-kinase catalytic alpha and KRAS mutations are important predictors of resistance to therapy with epidermal growth factor receptor tyrosine kinase inhibitors in patients with advanced non-small cell lung cancer. J Thorac Oncol 6: 707-715, 2011.

32. Ho CC, Liao WY, Lin CA, Shih JY, Yu CJ and Yang JC: Acquired BRAF V600E Mutation as Resistant Mechanism after Treatment with Osimertinib. J Thorac Oncol 12: 567-572, 2017.

33. Del Re M, Tiseo M, Bordi P, D'Incecco A, Camerini A, Petrini I, Lucchesi M, Inno A, Spada D, Vasile E, et al: Contribution of KRAS mutations and c.2369C > T (p.T790M) EGFR to acquired resistance to EGFR-TKIs in EGFR mutant NSCLC: A study on circulating tumor DNA. Oncotarget 8: 13611-13619, 2017.

34. Eberlein CA, Stetson D, Markovets AA, Al-Kadhimi KJ, Lai Z, Fisher PR, Meador CB, Spitzler P, Ichihara E, Ross SJ, et al: Acquired Resistance to the Mutant-Selective EGFR Inhibitor AZD9291 Is Associated with Increased Dependence on RAS Signaling in Preclinical Models. Cancer Res 75: 2489-2500, 2015. 
35. Kim JY, Welsh EA, Fang B, Bai Y, Kinose F, Eschrich SA Koomen JM and Haura EB: Phosphoproteomics Reveals MAPK Inhibitors Enhance MET- and EGFR-Driven AKT Signaling in KRAS-Mutant Lung Cancer. Mol Cancer Res 14: 1019-1029, 2016.

36. Piotrowska Z, Niederst MJ, Karlovich CA, Wakelee HA, Neal JW, Mino-Kenudson M, Fulton L, Hata AN, Lockerman EL, Kalsy A, et al: Heterogeneity Underlies the Emergence of EGFRT790 Wild-Type Clones Following Treatment of T790M-Positive Cancers with a Third-Generation EGFR Inhibitor. Cancer Discov 5: 713-722, 2015.

37. Hirakawa H, Komiya K, Nakashima C, Ogusu S, Nakamura T, Tanaka M, Takahashi K, Egashira Y, Kai K, Kimura S, et al: A case of osimertinib-resistant lung adenocarcinoma responded effectively to alternating therapy. Ann Transl Med 6: 464, 2018.

38. Minari R, Bordi P, Del Re M, Facchinetti F, Mazzoni F, Barbieri F, Camerini A, Comin CE, Gnetti L, Azzoni C, et al: Primary resistance to osimertinib due to SCLC transformation: Issue of T790M determination on liquid re-biopsy. Lung Cancer 115: $21-27,2018$

39. Li X, Wang S, Li B, Wang Z, Shang S, Shao Y, Sun X and Wang L: BIM Deletion Polymorphism Confers Resistance to Osimertinib in EGFR T790M Lung Cancer: A Case Report and Literature Review. Target Oncol 13: 517-523, 2018

40. Tanimoto A, Takeuchi S, Arai S, Fukuda K, Yamada T, Roca X, Ong ST and Yano S: Histone Deacetylase 3 Inhibition Overcomes BIM Deletion Polymorphism-Mediated Osimertinib Resistance in EGFR-Mutant Lung Cancer. Clin Cancer Res 23: 3139-3149, 2017.
41. Iwama E, Sakai K, Azuma K, Harada D, Nosaki K, Hotta K, Nishio M, Kurata T, Fukuhara T, Akamatsu H, et al: Exploration of resistance mechanisms for epidermal growth factor receptor-tyrosine kinase inhibitors based on plasma analysis by digital polymerase chain reaction and next-generation sequencing. Cancer Sci 109: 3921-3933, 2018.

42. Labbé C, Cabanero M, Korpanty GJ, Tomasini P, Doherty MK, Mascaux C, Jao K, Pitcher B, Wang R, Pintilie M, et al: Prognostic and predictive effects of TP53 co-mutation in patients with EGFR-mutated non-small cell lung cancer (NSCLC). Lung Cancer 111: 23-29, 2017.

43. Ou SI, Cui J, Schrock AB, Goldberg ME, Zhu VW, Albacker L, Stephens PJ, Miller VA and Ali SM: Emergence of novel and dominant acquired EGFR solvent-front mutations at Gly796 (G796S/R) together with $\mathrm{C} 797 \mathrm{~S} / \mathrm{R}$ and $\mathrm{L} 792 \mathrm{~F} / \mathrm{H}$ mutations in one EGFR (L858R/T790M) NSCLC patient who progressed on osimertinib. Lung Cancer 108: 228-231, 2017.

44. Jang J, Son JB, To C, Bahcall M, Kim SY, Kang SY, Mushajiang M, Lee Y, Jänne PA, Choi HG, et al: Discovery of a potent dual ALK and EGFR T790M inhibitor. Eur J Med Chem 136: 497-510, 2017

(i) $(9)$ This work is licensed under a Creative Commons Attribution-NonCommercial-NoDerivatives 4.0 International (CC BY-NC-ND 4.0) License. 